\title{
AS QUEIXAS ESCOLARES NO SERVIÇO-ESCOLA: EVOLUÇÃO DOS CASOS
}

Lara Pelliciari Veríssimo

Universidade Federal do Triângulo Mineiro

Conceição Aparecida Serralha

Universidade Federal do Triângulo Mineiro
Recebido em: 05/11/2019

$1^{\text {a }}$ revisão em: 22/04/2020

Aceito em: 28/05/2020

\section{RESUMO}

As queixas escolares compreendem as dificuldades no processo de escolarização, seja de ordem pedagógica, relacional ou comportamental. Esta pesquisa teve como objetivo identificar as condutas adotadas e a evolução dos casos de crianças usuárias do serviço-escola de Psicologia da Universidade Federal do Triângulo Mineiro com queixas escolares, no período de 2013 a 2017, na faixa etária compreendida entre sete e 12 anos incompletos. Trata-se de uma pesquisa documental, com 60 prontuários analisados. Foram encontradas, na maioria dos prontuários, crianças do sexo masculino, de escola pública, e atendidas na modalidade de psicodiagnóstico. Foram observados grande desistência dos atendimentos, culpabilização da criança e da família, e pouco contato com a escola. Considera-se necessário compreender todos os ambientes nos quais a criança se encontra inserida.

Palavras-chave: psicologia; clínicas-escola; processos psicoterapêuticos. 


\section{SCHOOL COMPLAINTS IN A TEACHING-SERVICE: ASSISTANCE EVOLUTION}

\section{ABSTRACT}

School complaints include difficulties in the schooling process, such as pedagogical, socialization or behavioral. The study aimed to identify the conducts adopted and the psychological assistance evolution of children using the University Psychology teaching-service. Those selected children had to be with school complaints from 2013 to 2017 and between the ages of seven and 12 years. This is a documentary study, with 60 psychological records analyzed. Most of these records were of male children, from public schools, and attended in the modality of psychodiagnosis. The result shows a large drop in attendance, family's and child's blaming, and lack of contact with the school. It is considered necessary to understand all environments in which the child is into.

Keywords: psychology; teaching-service; psychotherapeutic processes.

\section{LAS QUEJAS ESCOLARES EN EL SERVICIO ESCOLAR: EVOLUCIÓN DE CASOS}

\section{RESUMEN}

Las quejas escolares comprenden las dificultades en el proceso de escolarización, sea pedagógica, de socialización o de comportamiento. La investigación tuvo como objetivo identificar las conductas adoptadas y la evolución de los casos de niños usuarios del servicio-escuela de Psicología de la Universidade Federal do Triângulo Mineiro con quejas escolares, entre 2013 a 2017, entre las edades de siete y 12 años incompletos. Es una investigación documental, con 60 registros psicológicos analizados. Se encuentra, en la mayoría de los registros, niños del sexo masculino, de escuela pública, y asistidos en la modalidad de psicodiagnóstico. Se observó que la responsabilidad recae en el niño y la familia, gran desistimiento de las asistencias y poco contacto con la escuela. Se considera necesario comprender todos los ambientes en que se inserta el niño.

Palabras clave: psicología; escuela clínica; procesos psicoterapéuticos. 


\section{INTRODUÇÃO}

A relação entre Educação e Psicologia está presente no Brasil muito antes da regulamentação da profissão de psicólogo, ocorrida em 1962. Entretanto, foi a partir desse processo que a Psicologia obteve cursos específicos para a sua formação e seus campos de atuação foram sendo delimitados: clínica, trabalho e educação. A Psicologia Escolar e Educacional passou a ter, então, uma prática profissional pautada na modalidade clínica, cujo foco era a atenção à dimensão individual do educando, atendendo as demandas de problemas de aprendizagem e distúrbios de comportamento (Oliveira-Menegotto \& Fontoura, 2015).

Nesse início, o psicólogo escolar era um profissional chamado para atender as crianças que apresentavam dificuldades no processo de escolarização, a partir de um viés puramente individualizante, no qual o aluno era o único responsável pelo seu mau desempenho escolar (Cunha, Dazzani, Santos \& Zucoloto, 2016). Nesse sentido, o psicólogo usava como instrumentos principais o psicodiagnóstico e a psicoterapia no atendimento dado a esse aluno, um atendimento tradicional e clínico, focado nos mecanismos intrapsíquicos e nas relações familiares, excluindo os processos e práticas escolares que permeavam as dificuldades apresentadas pela criança (Freller et al., 2001).

Diante dessa perspectiva, Collares e Moysés (1996) e Patto (1999) apontaram que a construção histórica da queixa escolar se deu a partir de termos biopsicológicos e de carência cultural devido a todo esse processo de inserção do psicólogo na escola como um profissional clínico. Assim, a interpretação da queixa escolar como um problema essencialmente psíquico, gerado por problemas cognitivos, psicomotores ou neurológicos presentes na criança, contribuiu para o processo de patologização dos problemas escolares, ou seja, se a criança apresentava algum problema relacionado ao âmbito escolar, ela era encaminhada para um especialista, geralmente médico psiquiatra ou psicólogo, e retornava para a escola com um laudo de alguma patologia para justificar tais comportamentos e dificuldades (Souza et al., 2014). Meira (2000) afirmou ser resultante dessa posição patologizante, a culpabilização do aluno pelo fracasso escolar, desconsiderando as múltiplas determinações da educação e dos processos de aprendizagem.

Winnicott, no entanto, emerge como um autor bastante relevante para compreender a relação entre o desenvolvimento do psiquismo humano e o ambiente, bem como a importância do início da vida escolar dos indivíduos, a partir de sua teoria psicanalítica sobre o amadurecimento emocional, possibilitando interpretações e reflexões sobre como as queixas escolares são constituídas (Ribeiro, 2004). Ao propor essa teoria, Winnicott trouxe a ideia de que todo indivíduo humano possui uma tendência inata ao amadurecimento e à integração em uma unidade, considerando-se que ele não é essa unidade individual no início da vida e que necessita que o ambiente forme com ele o que chamou de "dois-em-um", ou unidade ambiente-indivíduo. Nesse sentido, para 
que o indivíduo consiga essa integração, ele precisa e depende da presença de um ambiente facilitador para fornecer os cuidados necessitados por ele (Dias, 2012).

Dessa forma, o ambiente facilitador, que oferece as condições para o crescimento pessoal, tem uma importância particular ao se considerar as diferentes etapas do desenvolvimento do indivíduo. Se esse ambiente falha, as consequências para o amadurecimento pessoal são diversas para cada momento específico do desenvolvimento. Essa teoria, quando atrelada ao estudo da educação, traz ênfase maior sobre esses aspectos, ao compreender que o ambiente escolar pode ser considerado facilitador ou não para o desenvolvimento da criança (Ribeiro, 2004). Serralha (2016) aponta que, o "ambiente instituição" era reconhecido por Winnicott como complementar aos papéis parentais - na falta dos pais ou de seus substitutos -, sendo responsável por promover 0 desenvolvimento do indivíduo como ser social.

Por conseguinte, ao pensar a escola como uma instituição que também oferece cuidados para as crianças, ela pode ser situada em uma posição intermediária entre os cuidados iniciais do indivíduo e a ampliação para os agrupamentos sociais, com possibilidades de um crescimento sadio e/ou uma reparação das falhas ambientais no desenvolvimento inicial (Ribeiro, 2008). Assim, Ribeiro (2008) explicita a importância da escola em oferecer um bom manejo, considerando o desenvolvimento emocional das crianças, juntamente com os demais processos de desenvolvimento e aprendizagem, uma vez que a atenção e o bom cuidado propiciam o aprendizado e previnem demais problemas escolares. Para isso, Winnicott (1982/1964) sugere a realização de um diagnóstico educacional, no qual os professores, especializados e conhecedores do desenvolvimento infantil, identifiquem as necessidades refletidas nas dificuldades enfrentadas pelas crianças e, a partir disso, ofereçam os recursos ambientais necessários para um desenvolvimento sadio ou para a reparação de falhas do desenvolvimento inicial, que possam ter entravado o amadurecimento pessoal.

Contudo, levando-se em conta que algumas escolas brasileiras têm dificuldades em atender as necessidades de seus alunos, Ribeiro (2004) enfatiza que, se o ambiente falhar de maneira superior às condições que o indivíduo consegue suportar, uma instabilidade pode ser ocasionada e culminar em um adoecer psíquico. Nesse sentido, a identificação das falhas do ambiente escolar pode auxiliar na compreensão da etiologia das dificuldades escolares apresentadas pelas crianças, uma vez que os problemas de aprendizagem não estão somente relacionados às causas orgânicas ou de um ambiente familiar não satisfatório.

Essa perspectiva somada às grandes transformações, que a Psicologia Escolar e Educacional vem sofrendo em sua maneira de atuar, corrobora a necessidade de compreensão adequada da queixa escolar, desde as suas possíveis causas até o acompanhamento psicológico, auxiliando na construção dos novos saberes científicos pertinentes à construção do campo teórico e prático dessa área 
(Cunha et al., 2016). Além disso, há um grande aumento dessas queixas chegando aos serviços de saúde, sobretudo advindas de escolas públicas (Dazzani, Cunha, Luttigards, Zucoloto, \& Santos, 2014), o que demonstra a necessidade de realizar um levantamento e uma análise detalhados das queixas escolares para possibilitar discussões acerca da prática do psicólogo escolar, assim como do psicólogo clínico, como forma de refletir as possíveis interlocuções no trabalho prático entre esses dois campos de atuação (Rodrigues, Campos, \& Fernandes, 2012).

Em um levantamento feito por Wielewicki (2011) para caracterizar os atendimentos de crianças em clínicas-escola brasileiras, nos últimos dez anos da pesquisa, os resultados apontaram predominância do sexo masculino, com idade entre seis e nove anos, sendo os principais motivos para encaminhamento o comportamento agressivo e problemas de aprendizagem. Em outras pesquisas realizadas (Nakamura, Lima, Tada, \& Junqueira, 2008; Rodrigues et al., 2012; Scortegagna \& Levandowski, 2004), há a caracterização das queixas escolares específicas para cada serviço de atendimento, também envolvendo majoritariamente as queixas do público masculino e relacionadas ao comportamento e aprendizagem, além de ser possível verificar a prevalência das escolas públicas nessas queixas. Já o levantamento feito por Galindo, Sousa e Tamman (2019), de publicações realizadas sobre as modalidades de atendimentos em serviços-escola, aponta ser maioria os atendimentos clínicos com demandas referentes aos contextos educacionais.

Pelo fato de os serviços-escola de Psicologia oferecerem atendimento à comunidade e receberem grande demanda de queixas escolares, eles desempenham papel fundamental na formação do psicólogo. As atividades realizadas nesses dispositivos estão relacionadas a diversos fatores que visam contribuir para que as universidades cumpram sua função social. Dessa forma, o serviço-escola deve constantemente estar em comunicação com os outros setores da comunidade na qual se insere para identificar e caracterizar as demandas específicas desta, proporcionando aos alunos estagiários os conhecimentos necessários para uma atuação mais eficaz frente a essas demandas (Amaral et al., 2012).

Ao se compreender, assim, a finalidade dos serviços-escola de oferecer tanto treinamento para os estagiários no período da graduação, quanto atendimento à população menos favorecida (Amaral et al., 2012), foi realizada uma pesquisa com o objetivo de contribuir para a caracterização das queixas escolares mais frequentes no Centro de Estudos e Pesquisa em Psicologia Aplicada (CEPPA), serviço-escola de Psicologia da Universidade Federal do Triângulo Mineiro (UFTM). Entendeu-se que esse conhecimento poderia proporcionar subsídios para orientação mais adequada aos estagiários de psicologia, possibilitando-lhes, no serviço-escola, desenvolver práticas de acordo com a demanda da população atendida (Amaral et al., 2012). 
O presente estudo, portanto, apresenta os resultados dessa pesquisa, que teve como objetivo geral identificar as condutas adotadas e a evolução dos casos de crianças usuárias do serviço-escola com queixas escolares, atendidas no período de 2013 a 2017, com faixa etária entre sete e 12 anos incompletos. Como objetivos específicos, o estudo buscou caracterizar os tipos de queixas escolares assistidas no CEPPA; investigar se o diagnóstico do caso, após o início do tratamento, correspondeu à queixa inicial de dificuldades escolares e averiguar como a escola foi vista em relação às queixas no atendimento da criança. Cabe ressaltar que a pesquisa não teve por finalidade estudar as queixas específicas encontradas, mas oferecer um panorama dos atendimentos oferecidos à população a partir das queixas manifestadas.

\section{MÉTODO}

O estudo constitui-se em uma pesquisa documental, amparada na abordagem qualitativa de pesquisa. Kripka, Scheller e Bonotto (2015) apontam que a pesquisa documental utiliza fontes primárias de informações, ou seja, utiliza documentos que ainda não foram analisados e sistematizados anteriormente, para compreender uma realidade ou um determinado fenômeno. Ainda, para os autores, na pesquisa documental, o pesquisador deve selecionar, tratar e interpretar as informações coletadas visando tornar os dados mais significativos ao responder os questionamentos iniciais da pesquisa.

\section{MATERIAL}

Foram utilizados prontuários de crianças arquivados no CEPPA, que atenderam aos seguintes critérios de inclusão: (a) prontuários arquivados no período de 2013 a 2017; (b) prontuários cujas queixas principais estavam relacionadas a queixas escolares, e (c) prontuários de crianças com idade entre sete e 12 anos incompletos no início dos atendimentos, independente do sexo. Foram excluídos os prontuários cujos tratamentos não progrediram o suficiente para fornecer os dados necessários à pesquisa, ou seja, aqueles que apresentaram interrupção dos atendimentos sem a compreensão detalhada da demanda ou aqueles com menos de quatro sessões. A faixa etária foi delimitada a partir da revisão de literatura realizada para a construção da pesquisa, na qual é identificada a primeira etapa da educação básica como o período de prevalência das queixas em crianças (Boaz \& Nunes, 2009; Dazzani et al., 2014; Nakamura et al., 2008; Rodrigues et al., 2012).

\section{CENÁRIO DA PESQUISA}

O serviço-escola de Psicologia (CEPPA) é uma área suplementar da Universidade Federal do Triângulo Mineiro (UFTM), vinculada ao Instituto de Educação, Letras, Artes, Ciências Humanas e Sociais (IELACHS) da cidade de Uberaba, Minas Gerais. Em seu regimento interno consta a dupla função a ser exercida pelo serviço: a de ensino, para a formação de graduandos em Psicologia, e a de assistência, 
oferecendo atendimento psicológico à comunidade. Para atingir tais objetivos, o CEPPA prevê possibilitar o desenvolvimento de atividades nas várias áreas de aplicação da Psicologia (Simões, 2016). Entretanto, o serviço-escola tem oferecido, majoritariamente, atendimentos na área clínica e individuais.

\section{PROCEDIMENTO DE COLETA E ANÁLISE DE DADOS}

Após a autorização da coordenação do CEPPA para a realização da pesquisa e aprovação do projeto no Comitê de Ética em Pesquisa, os prontuários foram identificados e separados, sendo observados os itens: dados da ficha de entrada; queixa declarada; dados escolares da criança; a compreensão do problema; as condutas e a evolução dos casos.

A análise dos dados utilizada foi a Análise de Conteúdo de Bardin (2011), que se constitui em uma metodologia de pesquisa para descrever e interpretar o conteúdo de documentos. Nessa análise, utiliza-se a descrição sistemática para o desvendamento crítico, ou seja, para reinterpretar as mensagens e atingir uma compreensão de seus significados para além da leitura comum. Posteriormente, para a discussão dos resultados, foi utilizado o referencial teórico psicanalítico winnicottiano, bem como a literatura revisada.

\section{ASPECTOS ÉTICOS}

O desenvolvimento desta pesquisa está de acordo com as exigências éticas previstas na resolução n 466, de 12/12/2012 do Conselho Nacional de Saúde, a respeito de estudos envolvendo seres humanos, de forma direta ou indireta. Ainda, a pesquisa fui submetida ao Comitê de Ética em Pesquisa da Universidade Federal do Triângulo Mineiro (CEP-UFTM), recebendo parecer favorável $n^{\circ}$ 2.594.257.

\section{RESULTADOS E DISCUSSÃO}

Para se compreender como o serviço-escola atendeu crianças com queixas escolares no período de 2013 a 2017, foram selecionados 60 prontuários para análise dos atendimentos realizados, de acordo com os critérios de inclusão e exclusão. Nesses prontuários, a condução dos atendimentos foi realizada apenas por estudantes estagiários de Psicologia que cursavam os períodos finais do curso - sétimo, oitavo, nono e décimo períodos -, supervisionados por seus professores.

É importante ressaltar que as fichas de cadastro do usuário no CEPPA são preenchidas pelo próprio usuário ou pelo responsável, no caso de menores de idade. Nessas fichas são anexados, quando possuem, os papéis de encaminhamento de outras instituições ou serviços, não sendo estes definidores da prioridade do atendimento. Tal prioridade, no serviço-escola, era definida a partir da ordem cronológica de cadastro, mas recebia interferência de certos 
fatores como a disponibilidade do usuário ao ser chamado para atendimento, uma vez que, devido à grande demanda no serviço, alguns usuários eram contatados meses após o cadastro ser realizado, assim como a disponibilidade de frequentar o serviço no mesmo horário em que o estagiário estava disponível.

Para a pesquisa, foram selecionados os prontuários dos casos atendidos, cujas queixas principais eram escolares. Após análise, percebeu-se que alguns dos atendimentos ocorreram independentemente da presença de encaminhamentos. Os resultados obtidos são apresentados e discutidos a partir de três eixos temáticos: (a) caracterização das queixas escolares; (b) modalidade, diagnóstico e evolução dos atendimentos, e (c) perspectivas sobre o ambiente escolar.

\section{CARACTERIZAÇÃO DAS QUEIXAS ESCOLARES}

Inicialmente, é preciso destacar que a análise dos prontuários ocorreu a partir da leitura de dois modelos diferentes de fichas de triagem. Antes do ano de 2016, essas fichas eram sucintas, contendo apenas os dados pessoais - sexo, idade, endereço, profissão e procedência - e a descrição das queixas primária e secundária trazidas pelos usuários. A partir de 2016, as fichas foram remodeladas para conter mais informações pessoais, socioeconômicas e especificações sobre a demanda, além de apresentar melhor categorização das queixas. Entretanto, mesmo com a reformulação da ficha de triagem, não foi designado espaço específico para registrar os dados escolares dos usuários.

Para melhor visualização dos dados obtidos, referentes às categorias de queixas escolares encontradas, os resultados foram sintetizados como se apresentam na Tabela 1. Cabe ressaltar que as categorias dessa tabela foram criadas a partir da leitura dos registros das sessões iniciais de cada atendimento, que possibilitaram o agrupamento das queixas declaradas pelos responsáveis das crianças. Dessa forma, alguns comportamentos aparecem em mais de uma categoria, pois foram identificados de maneira isolada ou conjunta com outros tipos de comportamentos.

A categoria "outras queixas comportamentais" compreendeu queixas relacionadas à inquietação, agitação, impulsividade e agressividade, que apareceram juntas ou separadamente. Por não serem identificadas, pelos responsáveis da criança ou pelos estagiários, como hiperatividade, nas sessões iniciais, optou-se por manter os termos conforme constaram nos prontuários. Já na categoria "outras queixas comportamentais e dificuldades de aprendizagem", foram incluídos casos de encoprese na escola, lentidão, falta de concentração e timidez associados às dificuldades na aprendizagem. Por último, a categoria "outras dificuldades de aprendizagem" englobou dificuldades na memória e na aquisição de pensamento abstrato. 
Tabela 1

Caracterização das queixas escolares do CEPPA.

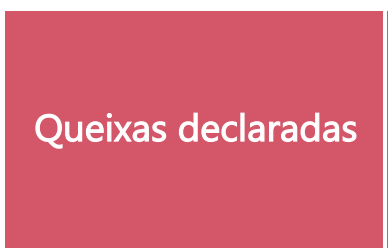

Dificuldades na leitura e escrita Hiperatividade e dificuldades de aprendizagem

Agressividade /indisciplina e dificuldades de aprendizagem

Desinteresse, desmotivação, desatenção

Agressividade

Brigas com colegas

e agressividade

Outras queixas comportamentais

Outras queixas comportamentais e dificuldades de aprendizagem

\section{Bullying e}

dificuldades de aprendizagem

Dificuldades na socialização

Outras dificuldades de aprendizagem

\begin{tabular}{cccccc}
\hline Total & 60 & $100 \%$ & $45 / 15$ & - & $49 / 5 / 6$ \\
\hline Porcentagem & 100 & - & $75 / 25$ & - & $81,7 / 8,3 / 10$ \\
\hline
\end{tabular}

Foi possível perceber que a categoria isolada predominante é a de crianças com dificuldades apenas na aprendizagem da leitura e escrita. Entretanto, quando 
analisada a coocorrência de dificuldades de aprendizagem e problemas comportamentais - hiperatividade, agressividade/indisciplina, bullying e outras queixas - o número ultrapassa $31,7 \%$ dos casos (19 casos). Esse resultado vai ao encontro de pesquisas realizadas em outros serviços de atendimento psicológico, nas quais se encontrou a predominância de queixas de dificuldades de aprendizagem associadas a queixas comportamentais (Braga \& Morais, 2007; Gomes \& Pedrero, 2015; Rodrigues et al., 2012). Rodrigues et al. (2012) afirmam ainda que as queixas múltiplas são mais frequentes nos encaminhamentos de crianças com demandas escolares.

Em contrapartida, ao se observar as queixas de aprendizagem e as queixas comportamentais, sem coocorrência entre as duas, a diferença entre ambas é pequena: as queixas de aprendizagem somam $26,6 \%$ (16 casos), enquanto as comportamentais somam 28,3\% (17 casos). A sobreposição das queixas comportamentais ocorre no estudo de Gomes e Pedrero (2015) em maior proporção, mas difere das outras pesquisas, nas quais as queixas de aprendizagem aparecem em número maior que as comportamentais (Braga \& Morais, 2007; Cunha et al., 2016; Nakamura et al., 2008; Rodrigues et al., 2012). Ainda, as queixas referentes às dificuldades de socialização no ambiente escolar apresentam menor número tanto no presente estudo, quanto nos estudos referidos anteriormente.

A partir dos resultados expostos, faz-se necessária uma reflexão sobre a relação entre as dificuldades de aprendizagem e as queixas comportamentais. Nesse sentido, Marturano e Elias (2016) discutem essa relação estabelecendo uma associação na qual o baixo desempenho escolar aparece como preditor dos comportamentos externalizantes e agressivos, nas séries mais avançadas do ensino fundamental. Não obstante, as autoras também mostram que essa associação é inversa na pré-escola e nas séries iniciais, ou seja, os comportamentos externalizantes são os preditores do baixo desempenho. Desse modo, elas pontuam que há uma influência entre os dois fatores, a depender do estágio em que a criança se encontra, e que há também influências do ambiente familiar no aparecimento desses comportamentos - como, por exemplo, atividades compartilhadas entre os familiares, passeios, tempo livre, rotina doméstica diária e adversidades familiares. Assim, o estudo destaca a importância de se compreender esses problemas como resultados de interações e não como atributos do indivíduo. Nessa perspectiva, ao se pensar na teoria winnicottiana, Ribeiro (2004) enfatiza a necessidade de identificar as falhas do ambiente escolar, assim como de todos os ambientes em que a criança está inserida, para compreender como se dão essas relações e intervir, de maneira eficaz, nas dificuldades apresentadas pela criança, permitindo que o ambiente seja facilitador para o seu desenvolvimento.

No tocante à questão de gênero, este estudo encontrou $75 \%$ dos casos (45 casos) referentes ao sexo masculino. Do mesmo modo, o predomínio da população masculina nos atendimentos às queixas escolares parece ser uma 
constante em vários estudos (Boaz \& Nunes, 2009; Braga \& Morais, 2007; Gomes \& Pedrero, 2015; Nakamura et al., 2008; Rodrigues et al., 2012; Wielewicki, 2011). Braga e Morais (2007) explicam a preponderância de encaminhamentos de crianças do sexo masculino para atendimento psicológico por razões socioculturais: os perfis sociais designados para meninos e meninas são diferentes e, com isso, os comportamentos esperados e exigidos pela escola também são distintos. Assim, é possível pensar que as escolas, que encaminharam ou incentivaram a busca por atendimento psicológico, podem ter um conjunto de regras e atitudes esperadas, que consideram mais adequadas para as crianças, aproximando ambos os gêneros. Gomes e Pedrero (2015) corroboram esse pensamento, ao afirmarem que a escola, ao detectar comportamentos indesejáveis, parece se antecipar na indicação de acompanhamento profissional para assegurar um padrão de obediência e evitar o risco de delinquência, uma vez que os meninos são percebidos, geralmente, como mais ativos e indisciplinados que as meninas.

No que tange às esferas pública e privada características das escolas, foi possível verificar que $81,7 \%$ (49 casos) das crianças atendidas pertencem a escolas da rede pública. Esse alto percentual coincide com as pesquisas levantadas na literatura, cujas crianças em atendimento psicológico nos serviços públicos de saúde são, em grande maioria, advindas de escolas públicas (Boaz \& Nunes, 2009; Braga \& Morais, 2007; Dazzani et al., 2014; Gomes \& Pedrero, 2015; Nakamura et al., 2008; Rodrigues et al., 2012; Scortegagna, \& Levandowski, 2004). Não obstante, foi observado que, em $10 \%$ dos prontuários (6 casos), o nome das escolas não foi mencionado, nem na ficha de inscrição preenchida pelos responsáveis da criança, nem no preenchimento da demanda feito pelos estagiários. Na perspectiva de Souza (2007), a não menção do nome da escola nos prontuários reforça a ideia de que a questão individual e familiar se sobrepõe às concepções críticas sobre o ambiente escolar no atendimento dado ao usuário do serviço. Isso, também, leva a inferir que, nessa porcentagem de casos, a escola não foi procurada durante o atendimento da criança para ser ouvida ou participar da solução das queixas.

No tocante à faixa etária das crianças atendidas com queixas escolares, este estudo evidencia que todas as categorias de queixas encontradas ocorreram em faixas de idade diferentes, dentro do critério de idade estipulado para a pesquisa. Essa faixa etária estipulada corrobora a literatura revisada, que apresenta estudos identificando a prevalência das queixas em crianças com idades correspondentes à primeira etapa da educação básica (Boaz \& Nunes, 2009; Dazzani et al., 2014; Nakamura et al., 2008; Rodrigues et al., 2012).

\section{MODALIDADE, DIAGNÓSTICO E EVOLUÇÃO DOS ATENDIMENTOS}

Foram encontradas quatro modalidades diferentes de atendimento para as queixas escolares, sendo elas: psicodiagnóstico, psicoterapia, acolhimento e plantão psicológico. A modalidade psicodiagnóstico compreende uma variante 
de atendimentos realizados a partir de psicodiagnóstico interventivo e a modalidade psicoterapia compreende atendimentos grupais e individuais. De acordo com as queixas encontradas nos prontuários, a Tabela 2 ilustra as queixas que foram atendidas nessas modalidades.

Foi possível observar que a modalidade predominante foi o psicodiagnóstico, tanto nos casos atendidos somente nessa categoria (28,3\% - 17 casos), quanto nos casos que associaram psicodiagnóstico e outra modalidade $(38,3 \%$ - 23 casos). Esse percentual vai ao encontro dos números encontrados na literatura, que revelaram que os atendimentos às queixas escolares nos serviços de Psicologia vêm acontecendo, majoritariamente, no modelo de psicodiagnóstico (Freller, 2001; Nakamura et al. 2008; Souza, 2007).

Essa modalidade, referente ao atendimento de queixa escolar, é entendida por Nakamura et al. (2008) como uma ferramenta para diagnosticar e avaliar o que está por trás da queixa, ou seja, detectar se é uma dificuldade de ordem emocional da criança ou uma questão pedagógica e, para isso, são utilizados instrumentos e testes de avaliação psicológica. Nos prontuários analisados, as condutas dos estagiários que atenderam em psicodiagnóstico não diferem do exposto pelos autores mencionados, uma vez que seguiram um padrão bastante parecido de atendimento: anamnese, hora lúdica com a criança, aplicação de testes e procedimentos psicológicos, bem como devolutiva para os responsáveis.

Neste estudo, oito dos 17 casos foram compreendidos, no psicodiagnóstico, oriundos de questões emocionais e familiares influenciadoras das dificuldades escolares da criança e foram encaminhados para psicoterapia. Entretanto, nesses casos, os responsáveis desistiram do atendimento ou não conseguiram ser contatados por telefone para dar a continuidade ao atendimento. Em seis casos do total foram constatadas dificuldades no âmbito escolar sem outras questões associadas e foram encaminhados para serviços especializados de fonoaudiologia e educação especial da cidade. Nota-se que o encaminhamento feito não deixou de colocar a criança como aquele que deverá ser tratado. Os três casos restantes receberam alta, pois, embora tenham sido observadas pequenas dificuldades na escolarização, não havia queixas significativas para encaminhamentos, ou demanda para psicoterapia. Nessas situações, os estagiários ofereceram devolutivas com orientações aos responsáveis da criança, mas não houve evidência de devolutiva para a escola.

É importante destacar que a modalidade de psicodiagnóstico, como aponta Krug, Trentini e Bandeira (2016), é um processo complexo de avaliação e intervenção, que, ao elaborar uma hipótese diagnóstica, amparada em uma compreensão teórica, identifica os pontos importantes a serem trabalhados no avaliando, sugerindo encaminhamentos e intervenções para o benefício deste. Nesse sentido, de uma perspectiva winnicottiana, Salles e Tardivo (2017) compreendem que o processo de avaliação no psicodiagnóstico deve envolver também um diagnóstico relacional, através do uso dialógico de instrumentos de avaliação - 
como exemplos, os instrumentos projetivos e atividades lúdicas - para que a criança possa se expressar espontaneamente. Assim, a criança revelaria o grau de integração em seu desenvolvimento emocional, possibilitando uma intervenção de acordo com a compreensão desse aspecto, para além das dificuldades encontradas nos testes psicométricos comumente utilizados no psicodiagnóstico.

Na segunda maior categoria de atendimentos encontrada - psicodiagnóstico seguido de psicoterapia (25\% - 15 casos) - o encaminhamento para a psicoterapia aconteceu devido a várias questões emocionais observadas na criança e no seu contexto familiar, que foram consideradas importantes de serem trabalhadas. Dentre essas questões, ficou mais evidente a ansiedade, a dificuldade de manter relacionamento com pares e conflitos familiares (separação dos pais, ausência paterna e dificuldade na relação com os pais). Assim, no processo de psicoterapia, os estagiários nortearam suas condutas para tratar essas problemáticas, utilizando jogos e atividades lúdicas com as crianças. Foram trabalhados os sentimentos que acompanhavam suas dificuldades e realizadas sessões com os responsáveis para compreenderem melhor o contexto familiar e oferecerem orientações.

No que tange à evolução dos casos que passaram por psicoterapia após o psicodiagnóstico, sete dos 15 casos desistiram dos atendimentos quando houve encaminhamento para sua continuidade com um novo estagiário. Ainda, três casos foram arquivados por faltas injustificadas e consecutivas, atendendo às regras do serviço-escola que orientam as condutas dos estagiários. Do restante, três receberam alta por apresentarem melhora nas dificuldades encontradas, um foi encaminhado para outro serviço em saúde mental da rede e um não foi possível ser contatado por telefone para ser chamado novamente para a psicoterapia.

Sobre a modalidade acolhimento, Neumann e Zordan (2011) entendem que esse modo de atendimento, apesar de ter caráter de triagem, busca uma investigação mais detalhada das queixas trazidas pelos indivíduos, assim como proporciona maior vinculação entre terapeuta e usuário, quando comparado ao processo de triagem, que se destina a colher dados e classificar a urgência do atendimento. No serviço-escola desta pesquisa, essa modalidade de atendimento destinava-se a receber os usuários que fizeram as inscrições no serviço para compreender a demanda e identificar a prioridade do caso. Nos prontuários analisados para este estudo, os casos que passaram somente pelo acolhimento (11,6\% - sete casos) apresentaram semelhanças em suas queixas: a criança apresentava dificuldades típicas do período de desenvolvimento e os conflitos familiares permeavam a queixa declarada. Nesse sentido, três dos sete casos tiveram alta, com orientações aos responsáveis e encaminhamento dos familiares para psicoterapia; dois foram arquivados por faltas injustificadas e dois também foram encaminhados - um para psicoterapia e outro para psicodiagnóstico. Destes, o primeiro não conseguiu ser contatado e o segundo desistiu da continuidade do atendimento em psicodiagnóstico. 
Tabela 2

Modalidades de atendimentos das queixas escolares.
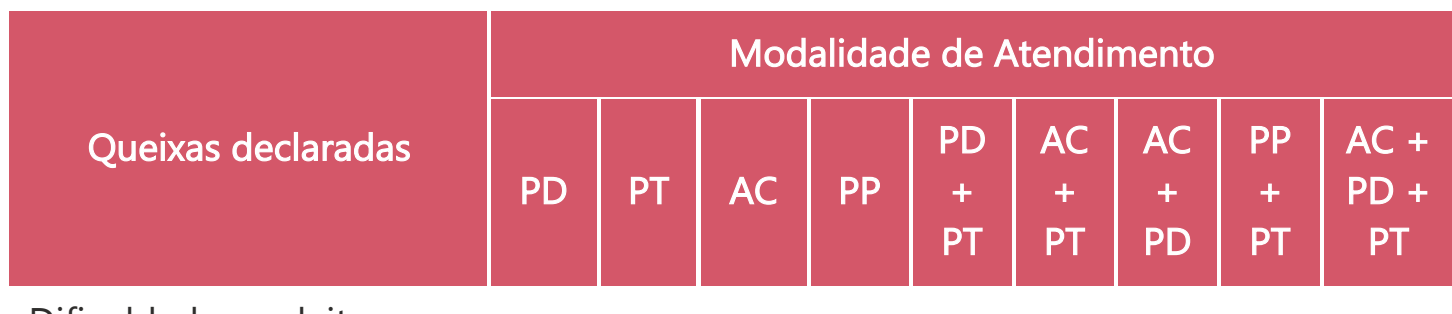

Dificuldades na leitura e escrita

$\begin{array}{llllll}5 & 1 & - & 1 & 6 & 1\end{array}$

Hiperatividade e

dificuldades de

aprendizagem

Agressividade /indisciplina e dificuldades de aprendizagem

Desinteresse, desmotivação, desatenção

Agressividade

Brigas com colegas e agressividade

Outras queixas comportamentais

Outras queixas comportamentais e dificuldades de aprendizagem

Bullying e dificuldades de aprendizagem

Dificuldades na socialização

Outras dificuldades de aprendizagem

\begin{tabular}{cccccccccc}
\hline Total & 17 & 2 & 7 & 3 & 15 & 6 & 6 & 2 & 2 \\
\hline Porcentagem & 28,3 & 3,3 & 11,6 & 5 & 25 & 10 & 10 & 3,3 & 3,3 \\
\hline
\end{tabular}

Nota. Legenda = PD: psicodiagnóstico; PT: psicoterapia; AC: acolhimento; PP: plantão psicológico. 
Os casos que passaram pelo acolhimento e foram encaminhados e atendidos em psicodiagnóstico ( $10 \%$ - seis casos) - por terem sido compreendidos como dificuldades emocionais ou cognitivas das crianças - também apresentaram maior número de faltas e desistência do atendimento, sendo apenas dois dos seis casos encaminhados para outros serviços de apoio pedagógico da rede municipal. Já os que foram compreendidos, no acolhimento, como sendo os conflitos familiares e as dificuldades nos relacionamentos as questões de maior relevância a serem trabalhadas, foram encaminhados e atendidos posteriormente em psicoterapia (10\% - seis casos). Desses casos, dois desistiram da psicoterapia e quatro foram desligados do serviço por faltas consecutivas e injustificadas.

A modalidade de plantão psicológico foi a menos presente no estudo. Daher, Ortolan, Sei e Victrio (2017) caracterizam esse atendimento como um tipo de intervenção psicológica pontual, sendo o mais próximo possível da necessidade do indivíduo, além de oferecer também um esclarecimento sobre a demanda deste. Apesar de essa modalidade de atendimento não ter caráter de triagem, no CEPPA, aqueles casos em que é identificada a necessidade de um acompanhamento maior são encaminhados para outras modalidades de atendimento no serviço. Nos casos analisados neste estudo, esse modo de atendimento ocorreu com mais de uma sessão, tendo em média de quatro a cinco encontros, nos quais houve conversas com os responsáveis, bem como investigação e intervenção mais diretas com a criança sobre as dificuldades relatadas. Dos três casos atendidos, um teve evolução para a alta dos atendimentos e dois foram encaminhados para psicoterapia. Contudo, ao serem chamados para esta, desistiram de dar continuidade ao tratamento. Aqueles casos em que ocorreram atendimentos em psicoterapia após o plantão psicológico (3,3\% - dois casos), também não apresentaram adesão ao tratamento, havendo desistência após algumas sessões.

Em suma, cabe destacar o alto percentual de evasão do serviço: 33,3\% dos casos (20 casos) desistiram do atendimento, 25\% (15 casos) tiveram seus prontuários arquivados por faltas injustificadas e em 5\% (3 casos) não houve possibilidade de contato pelos números de telefone. A literatura traz alguns estudos (Benetti \& Cunha, 2008; Sei \& Colavin, 2016) sobre o abandono e a desistência do processo psicoterápico, esclarecendo que são múltiplas as causas para essa problemática: não adesão à psicoterapia, frágil aliança com o terapeuta, problemas institucionais, questões particulares do indivíduo, tempo de espera para o atendimento, troca de terapeuta, entre outros. Desse modo, Sei e Colavin (2016) discutem a importância de se verificar as causas do abandono para que o serviço possa rever a oferta de atendimentos, de forma a atender as reais necessidades dos usuários e diminuir o índice de evasão.

Outra questão de destaque, nos prontuários analisados, foi a formulação de diagnósticos a partir das questões emocionais e cognitivas das crianças ou de aspectos referentes ao contexto familiar em que estão inseridas. Em nenhum dos casos houve uma investigação mais apurada junto à escola, para averiguar a 
responsabilização desta na produção da queixa, pois, mesmo nos atendimentos em que os estagiários realizaram visitas às escolas - que serão mais bem discutidos no próximo eixo -, os diagnósticos estavam mais relacionados às questões referidas anteriormente. Nesse sentido, Leonardo, Lemes e Facci (2016) reforçam que as queixas escolares são ainda explicadas por meio de visões tradicionais, que centralizam a problemática no indivíduo e na sua dinâmica familiar. Esses autores apontam a necessidade de uma visão mais ampla para o entendimento da queixa escolar, a fim de que se possa enxergar para além do indivíduo e de sua família.

Não obstante, há de se pensar sobre o cuidado às crianças que realmente apresentam tais dificuldades emocionais e cognitivas. Winnicott (1997/1996) considera que a escola, por vezes, tem um papel superior à proposição de ensino, pois, para as crianças difíceis, o ensino acaba tornando-se secundário ao manejo para o atendimento das necessidades dessas crianças. Tal pensamento evidencia ser indispensável às escolas a especialização dos professores, e também da equipe escolar, como forma de possibilitar a inclusão dos alunos com dificuldades, adequando o ambiente para oportunizar um desenvolvimento sadio ou para reparar as falhas do desenvolvimento inicial. Esse pensamento também deve ser refletido a partir do próprio serviço-escola em que as crianças são atendidas, no sentido de visualizar se o CEPPA, enquanto instituição, e os estagiários, enquanto agentes que propiciam o manejo e o cuidado dessas crianças, têm possibilitado o ambiente de cuidado das reais necessidades enfrentadas por elas, visto as evoluções dos atendimentos discutidas anteriormente.

\section{PERSPECTIVAS SOBRE O AMBIENTE ESCOLAR}

Dos sessenta prontuários analisados, somente em oito casos (13,3\%) foi realizado contato direto com a escola e, em outros dez $(16,7 \%)$ foi investigado o contexto escolar durante os atendimentos. Essa pequena parcela de contato com a escola, vai ao encontro da pesquisa de Dazzani et al. (2014), que evidenciou a ausência de contato com a instituição em vários atendimentos de queixas escolares. Os autores elucidam que falta a procura pelo entendimento das condições estruturais do local, assim como a identificação dos atores escolares participantes na produção da queixa. Souza (2007) discorre ainda sobre a não consideração da história de escolarização das crianças, sendo as visitas às escolas consideradas, por alguns estagiários e supervisores, apenas mais um dado a ser acrescentado aos prontuários.

Na presente pesquisa, não foi possível identificar os fatores que foram decisivos para a realização do contato com a escola, tampouco associá-lo a queixas ou modalidades de atendimentos específicos. Desse modo, infere-se que o contato com a escola, nos atendimentos realizados no CEPPA, parece ter sido determinado pela compreensão particular de cada estagiário, junto ao seu supervisor, e da necessidade de recolher mais informações sobre a criança. 
Nesse contexto, ressalta-se o papel dos professores supervisores de estágios, cujos conhecimentos e experiências práticas contribuem para a formação profissional dos estudantes. Silva Neto, Oliveira e Guzzo (2017) discorrem que a atuação dos supervisores visa auxiliar e instrumentalizar o estagiário na problematização de questões e na busca por respostas dentro da sua prática. Os autores apontam, ainda, não se tratar apenas de uma prática de ensino e aplicação de técnicas, mas uma prática para permitir que os estagiários usem estratégias analíticas para compreender a realidade e integrá-la às teorias, para assim questioná-las e modificá-las. Desse modo, cabe refletir sobre a importância de os supervisores de estágio no CEPPA manterem uma postura crítica e auxiliarem os estudantes a enxergarem a realidade dos casos trabalhados de forma mais ampla, que possibilite a articulação entre os saberes da prática clínica e do contexto escolar e educacional, no qual as crianças atendidas estão inseridas.

No registro feito pelos estagiários sobre as visitas às escolas e sobre as investigações realizadas, notou-se que as escolas são vistas de distintas maneiras: auxiliam nas dificuldades das crianças, responsabilizam os alunos e os pais pelas dificuldades das crianças, ou se mantêm neutras e indiferentes para com as dificuldades apresentadas. A constatação mais recorrente foi de escolas que utilizaram reprimendas e punições para tentar solucionar as dificuldades manifestadas pelas crianças, ou seja, crianças com queixas de comportamentos inadequados - agressividade, hiperatividade e outros - foram advertidas, suspensas ou trocadas de turma sem o consentimento das próprias crianças. Do mesmo modo, crianças com dificuldades na aprendizagem foram culpabilizadas pelo mau desempenho escolar e foram excluídas de atenção e educação individualizadas.

À vista disso, Ribeiro (2008), ancorada na teoria winnicottiana, afirma que a escola precisa inspirar segurança, protegendo as crianças de seus próprios impulsos e das possíveis consequências desastrosas destes, além de "resguardar a criança de possíveis intrusões do ambiente que sejam desfavoráveis ao seu crescimento" (p. 167). A autora acrescenta ainda que "quanto mais a criança puder ser tratada segundo o que é e sente que é, mais fortalecido torna-se o seu eu" (Ribeiro, 2008, p. 173). Ademais, Winnicott (1982/1964) considera que o papel dos professores e educadores é o de fornecer uma provisão ambiental, na qual o aluno consiga o atendimento de suas necessidades. Para isso, o autor evidencia a importância desses profissionais especializarem-se sobre o desenvolvimento emocional infantil e realizarem um diagnóstico educacional, a fim de detectar as necessidades de tais crianças e os manejos propiciadores do amadurecimento emocional.

Em alguns registros analisados, notaram-se escolas que culpabilizaram a organização familiar pelas dificuldades do aluno, assim como relataram suspeitas de negligência dentro desse contexto. Ribeiro (2008) enfatiza o discurso da escola que atribui às causas externas o não aprender e, dessa forma, a instituição 
não se organiza para atender às necessidades e resolver as problemáticas dos alunos. Essa atitude de distanciamento da escola, fomentada por diversas razões, quando pensada em relação às queixas escolares ou problemas de aprendizagem, evidencia uma falha ambiental, cuja origem não importa ao aluno, mas suas consequências são de extrema importância.

Em oposição a esse contexto, foram encontrados, nos prontuários analisados, registros com boas impressões do ambiente escolar, mesmo que em número menor. Nesses casos, os estagiários que visitaram as escolas notaram que a compreensão dos educadores se assemelhava às deles no tocante ao entendimento do caso. Foi observada ainda uma postura, por parte das escolas, de atender às necessidades dos alunos e de seus familiares, por meio de auxílio psicopedagógico e de aprendizagem, encaminhamentos para serviços sociais, reuniões para diálogo e acompanhamento da família. Nessas escolas, foi possível perceber o engajamento com o processo psicoterapêutico da criança, uma vez que os estagiários relataram receber pedidos das escolas sobre orientações quanto ao desenvolvimento do caso e, assim, ofereceram devolutivas com possíveis estratégias de conduta e de favorecimento da aprendizagem.

Constatou-se que essas escolas apresentam ou procuram estabelecer um ambiente facilitador para o crescimento de seus alunos. Ribeiro (2004) discorre que o bom ambiente não se atrasa nem se adianta em relação às possibilidades emocionais da criança, não obstruindo o desenvolvimento nem tentando forçar a sua ocorrência. Para a autora, o ambiente facilitador "sustenta, propicia o cuidado, o suprimento das necessidades que possibilitam o amadurecer" (p. 11). De acordo com Braunstein (2007), a escola é um espaço privilegiado para que as necessidades fundamentais da criança possam ser atendidas. Todavia, para isso, os problemas de aprendizagem e de conduta precisam ser enxergados para além de uma perspectiva produtiva ou funcional, de forma que o aluno possa estabelecer significativas relações com a aprendizagem e apropriar-se de suas experiências.

Por conseguinte, Braunstein (2007) descreve um modelo de atendimento breve e focal, baseado no referencial winnicottiano, que faz conexão entre a psicologia clínica e a escolar. Os atendimentos às queixas do âmbito escolar visam abandonar o foco no indivíduo e considerar o ambiente ao analisar a queixa. A autora discorre que se "a problemática é tratada como individual, a rede de relações que produz o fracasso se mantém e, embora o aluno possa obter sensíveis melhoras, será alvo de novas queixas produzidas por um ambiente inadequado" (Braunstein, 2007, p. 400).

Assim sendo, a autora propõe a valorização do aluno na condição de sujeito de sua própria história, acolhendo-o, movimentando e transformando as relações entre a criança, a escola e a família. Para isso, os atendimentos integram: entrevistas com os responsáveis; atendimentos com a criança para compreender como a queixa se configura e se expressa na vida desse aluno; questionário para 
os professores com perguntas reflexivas sobre a atual situação do aluno e dados sobre sua relação com a aprendizagem; visitas à escola para estabelecer uma relação horizontal com o professor e refletir conjuntamente sobre possíveis estratégias e intervenções orientadas à família, à escola e à criança (Braunstein, 2007).

\section{CONSIDERAÇÕES FINAIS}

O presente estudo buscou oferecer um panorama das queixas escolares que chegaram ao serviço-escola de Psicologia da UFTM, no período de 2013 a 2017. Os resultados apontaram que as crianças que chegaram ao CEPPA com dificuldades no âmbito escolar são em sua maioria do sexo masculino, advindas de escola pública e com queixas múltiplas de comportamento, aprendizagem e socialização. Além disso, o serviço disponibilizou, majoritariamente, para esses usuários, o atendimento em psicodiagnóstico. Esses resultados encontrados estão de acordo com a literatura pesquisada, sobre atendimentos às queixas escolares em outros serviços de Psicologia (Boaz \& Nunes, 2009; Braga \& Morais, 2007; Dazzani et al., 2014; Gomes \& Pedrero, 2015; Nakamura et al., 2008; Rodrigues et al., 2012; Scortegagna, \& Levandowski, 2004; Souza, 2007).

No estudo realizado por Galindo et al. (2019) fica evidente que as publicações sobre as modalidades de atendimentos nos serviços-escola tangenciam principalmente os atendimentos clínicos, sendo justificados pela história dos serviços-escola como uma clínica psicológica, mas também consideram que as outras atividades nesses serviços possam não estar sendo publicadas na literatura. Dessa forma, em relação ao presente estudo, percebe-se a necessidade de estudos que abordem as outras atividades oferecidas pelo CEPPA, uma vez que seu regimento interno (Simões, 2016) prevê o desenvolvimento de atividades nas diversas áreas da Psicologia e não somente na área clínica, como forma de identificar se as queixas escolares também estão sendo atendidas por outras modalidades e/ou se há um programa para a prevenção dessas queixas junto às escolas.

Foram encontrados, durante a pesquisa, prontuários que apresentaram poucos detalhes em relação aos atendimentos, por parte dos estagiários, o que caracteriza uma limitação do estudo, uma vez que os casos poderiam ter sido melhor analisados se tivessem maiores detalhes. Ademais, parte dos prontuários não continha de forma clara a conclusão do estagiário sobre o diagnóstico do caso e o motivo do encaminhamento para outras modalidades. De forma geral, constatou-se que os diagnósticos permeavam as questões emocionais e cognitivas das crianças e o seu contexto familiar.

Nesse sentido, a não referência ao ambiente escolar nos diagnósticos e a falta de contato com as escolas nos atendimentos analisados desta pesquisa evidenciam um modelo de atendimento clínico bastante clássico (Dazzani et al., 2014). Ao se pensar a clínica com crianças, Serralha (2016) demonstra a importância de se 
analisar com cuidado o ambiente da criança, tanto o ambiente imediato quanto o mais amplo, para melhor compreender os fatores que a conduzem a um bloqueio em seu desenvolvimento emocional, que pode afetar entre outras questões a sua aprendizagem. Assim, torna-se necessário, na compreensão da queixa escolar, investigar os contextos nos quais a criança está inserida, principalmente o contexto escolar, bem como a forma como esse ambiente está influenciando o seu desenvolvimento.

Com isso, o estudo evidencia a importância da articulação entre a área da psicologia clínica e a da educação, principalmente nos estágios oferecidos pelas universidades. Souza et al. (2014) mostram a necessidade de atuações que consigam articular os aspectos sociais, políticos e institucionais relacionados à queixa escolar. Destaca-se, assim, a necessidade da formação continuada dos professores supervisores para proporcionar reflexões sobre a prática profissional e construir novos meios para desenvolver o trabalho pedagógico, no sentido de orientar os supervisionandos para uma atuação crítica e integrada (Vasconcellos \& Sordi, 2016).

Do mesmo modo, Braunstein (2007) acredita que as intervenções no ambiente escolar são necessárias para o sucesso do atendimento a essas queixas e propõe um trabalho que abandona o foco no indivíduo e em sua família, fazendo com que o psicólogo configure novas intervenções, ultrapassando os limites do consultório e dos muros escolares. Do mesmo modo, Cunha et al. (2016) enfatiza a importância da parceria entre os serviços de saúde com as escolas para proporcionar uma atenção mais qualificada e integrada às queixas escolares.

O alto número de evasão dos usuários do serviço, encontrado na pesquisa, demonstra a necessidade de identificar os fatores decisivos para a desistência e abandono dos atendimentos, uma vez que a identificação das situações associadas ao abandono permite desenvolver ações preventivas tanto para o paciente quanto para o treinamento do profissional de psicologia (Benetti \& Cunha, 2008).

Assim, ao se considerar o CEPPA um serviço-escola que tem a função de oferecer assistência psicológica às demandas da comunidade, o estudo realça a necessidade de se refletir e repensar a atuação dos estagiários e dos supervisores frente às queixas escolares, de forma a proporcionar atendimentos com melhor evolução. Essa reflexão deve considerar se o funcionamento do serviço-escola está voltado mais para a formação acadêmica dos graduandos ou se realmente está implicado na assistência às demandas encontradas nos usuários, embora uma boa formação deva ser capaz de bem assistir essas demandas. Torna-se importante também um estudo que avalie as causas da desistência dos atendimentos oferecidos para as queixas escolares, que podem ter na autocrítica do serviço oferecido, a possibilidade de saná-las.

\section{REFERÊNCIAS}


Amaral, A. E. V., Luca, L., Rodrigues, T. C., Leite, C. A., Lopes, F. L., \& Silva, M. A. (2012). Serviços de psicologia em clínicas-escola: Revisão de literatura. Boletim de Psicologia, 62(136), 37-52.

Bardin, L. (2011). Análise de conteúdo. São Paulo, SP: Edições 70.

Boaz, C., \& Nunes, M. L. P. (2009). Caracterização das queixas de meninos e meninas em clínicasescola nos últimos 30 anos. Anais da IV Mostra de Pesquisa da Pós-Graduação da PUC. Porto Alegre, RS.

Braga, S. G., \& Morais, M. L. S. (2007). Queixa escolar: Atuação do psicólogo e interfaces com a educação. Psicologia USP, 18(4), 35-51. doi: 10.1590/S0103-65642007000400003

Benetti, S. P. C., \& Cunha, T. R. S. (2008). Abandono de tratamento psicoterápico: Implicações para a prática clínica. Arquivos Brasileiros de Psicologia, 60(2), 48-59.

Braunstein, V. C. (2007). Um atendimento em orientação à queixa escolar numa perspectiva winnicottiana: Muito além do indivíduo. In B. P. Souza (Ed.), Orientação à queixa escolar (pp. 399-414). São Paulo, SP: Casa do Psicólogo.

Collares, C. A. L., \& Moysés, M. A. A. (1996). Preconceitos no cotidiano escolar: Ensino e medicalização. São Paulo, SP: Cortez.

Cunha, E. O., Dazzani, M.V. M., Santos, G. L., \& Zucoloto, P. C. S. V. (2016). A queixa escolar sob a ótica de diferentes atores: Análise da dinâmica de sua produção. Estudos de Psicologia (Campinas), 33(2), 237-245. doi: 10.1590/1982-02752016000200006

Daher, A. C. B., Ortolan, M. L. M., Sei, M. B., \& Victrio, K. C. (2017). Plantão psicológico a partir de uma escuta psicanalítica. Semina: Ciências Sociais e Humanas, 38(2), 147-158. doi: 10.5433/1679-0383.2017v38n2p147

Dazzani, M. V. M., Cunha, E. O., Luttigards, P. M., Zucoloto, P. C. S. V., \& Santos, G. L. (2014). Queixa escolar: Uma revisão crítica da produção científica nacional. Psicologia Escolar $e$ Educacional, 18(3), 421-428. doi: 10.1590/2175-3539/2014/0183762

Dias, E. O. (2012). A teoria do amadurecimento de D. W. Winnicott. São Paulo, SP: DWW editorial.

Freller, C. C., Souza, B. P., Angelucci, C. B., Bonadio, A. N., Dias, A. C., Lins, F. R. S., \& Macêdo, T. E. R. (2001). Orientação à queixa escolar. Psicologia em Estudo, 6(2), 129-134. doi: 10.1590/S1413-73722001000200018

Galindo, W. C. M., Sousa, T. B. S., \& Tamman, B. F. (2019). Modalidades de atendimento à população por serviços-escola de Psicologia: Panorama das publicações. Gerais: Revista Interinstitucional de Psicologia, 12(2), 371-388. doi: 10.36298/gerais2019120212

Gomes, C. A. V., \& Pedrero, J. N. (2015). Queixa escolar: Encaminhamentos e atuação profissional em um município do interior paulista. Psicologia: Ciência e Profissão, 35(4), 1239-1256. doi: 10.1590/1982-3703002192013

Kripka, R. M. L., Scheller, M., \& Bonotto, D. L. (2015). Pesquisa documental: Considerações sobre conceitos e características na pesquisa qualitativa. Investigação Qualitativa em Educação, 2, 243-247.

Krug, J. S., Trentini, C. M., \& Bandeira, D. R. (2016). Conceituação de psicodiagnóstico na atualidade. In C. S. Hutz, D. R. Bandeira, C. M. Trentini, \& J. S. Krug (Eds.). Psicodiagnóstico. Porto Alegre, RS: Artmed Editora.

Leonardo, N. S. T., Lemes, M. J., \& Facci, M. G. D. (2016). O psicólogo diante da queixa escolar: Possibilidades de enfrentamento. Ensino em Re-Vista, 23(1), 275-302. doi: 10.14393/ERv23n1a2016-15

Marturano, E. M., Elias, L. C. S. (2016). Família, dificuldades no aprendizado e problemas de comportamento em escolares. Educar em Revista, 59, 123-139. doi: 10.1590/01044060.44617

Meira, M. E. M. (2000). Psicologia escolar: Pensamento crítico e práticas profissionais. In E. R. Tanamachi, M. L. Rocha, \& M. P. R. Proença (Eds.). Psicologia e Educação: Desafios teóricopráticos (pp. 35-12). São Paulo, SP: Casa do Psicólogo.

Nakamura, M. S., Lima, V. A. A., Tada, I. N. C., \& Junqueira, M. H. R. (2008). Desvendando a queixa escolar: Um estudo no serviço de Psicologia da Universidade Federal de Rondônia. Psicologia Escolar e Educacional, 12(2), 423-429. doi: 10.1590/\$1413-85572008000200013

Neumann, A. P., \& Zordan, E. P. (2011). A implantação do acolhimento na abordagem sistêmica em uma clínica-escola: possibilidades e desafios. Revista de Psicologia da IMED 3(1), 496-505. doi: 10.18256/2175-5027/psico-imed.v3n1p496-505

Oliveira-Menegotto, L. M., \& Fontoura, G. P. (2015). Escola e Psicologia: Uma história de encontros e desencontros. Revista Quadrimestral da Associação Brasileira de Psicologia Escolar e Educacional, 19(2), 377-385. doi: 10.1590/2175-3539/2015/0192869 
Patto, M. H. S. (1999). A produção do fracasso escolar: Histórias de submissão e rebeldia. São Paulo, SP: Casa do Psicólogo.

Ribeiro, M. J. (2004). Contribuições introdutórias para uma interlocução da obra de D. W. Winnicott e a psicología na escola. Winnicott e-prints, 3(1), 01-22.

Ribeiro, M. J. (2008). O início das vivências escolares: Contribuições da obra do psicanalista D. W. Winnicott. Aprender: Caderno de Filosofia e Psicologia da Educação, (11), 155-177.

Rodrigues, M. C., Campos, A. P. S., \& Fernandes, I. A. (2012). Caracterização da queixa escolar no Centro de Psicologia Aplicada da Universidade Federal de Juiz de Fora. Estudos de Psicologia (Campinas), 29(2), 241-252. doi: 10.1590/\$0103-166X2012000200010

Salles, R. J., \& Tardivo, L. S. P. C. (2017). Contribuições do pensamento de Winnicott para teoria e prática do psicodiagnóstico psicanalítico. Boletim Academia Paulista de Psicologia, 37(93), 282-310.

Scortegagna, P., \& Levandowski, D. C. (2004). Análise dos encaminhamentos de crianças com queixa escolar da rede municipal de ensino de Caxias do Sul. Interações, 9(18), 127-152.

Sei, M. B., \& Colavin, J. R, P. (2016). Desistência e abandono da psicoterapia em um serviço-escola de Psicologia. Revista Brasileira de Psicoterapia, 18(2), 37-49.

Serralha, C. A. (2016). O ambiente facilitador winnicottiano: Teoria e prática clínica. Curitiba, PR: CRV.

Silva Neto, W. M. F., Oliveira, W. A., \& Guzzo, R. S. (2017). Discutindo a formação em Psicologia: A atividade de supervisão e suas diversidades. Psicologia Escolar e Educacional, 21(3), 573582. doi: 10.1590/2175-353920170213111111

Simões, A. L. A. (2016). Centro de Estudos e Pesquisa em Psicologia Aplicada - CEPPA: Regulamento interno. Disponível em http://www.uftm.edu.br/ielachs/ceppa.

Souza, M. P. R. (2007). Prontuários revelando os bastidores do atendimento à queixa escolar. In B. P. Souza (Ed.), Orientação à queixa escolar (pp. 27-58). São Paulo, SP: Casa do Psicólogo.

Souza, M. P. R. et al. (2014). Atuação do psicólogo na educação: Análise de publicações científicas brasileiras. Psicologia da Educação, (38), 123-138.

Vasconcellos, M. M. M., \& Sordi, M. R. L. (2016). Formar professores universitários: Tarefa impossível? Interface, 20(57), 403-414. doi: 10.1590/1807-57622015.0450.

Wielewicki, A. (2011). Problemas de comportamento infantil: Importância e limitações de estudos de caracterização em clínicas-escola brasileiras. Temas em Psicologia, 19(2), 379-389.

Winnicott, D. W. (1982). A criança e o seu mundo (6 ed., A. Cabral, Trad.). Rio de Janeiro, RJ: LTC. (Trabalho original publicado em 1964).

Winnicott, D. W. (1997). Pensando sobre crianças (M. A. Veronese, Trad.). Porto Alegre, RS: Artes Médicas. (Trabalho original publicado em 1996).

\section{AGRADECIMENTOS}

As autoras agradecem ao CEPPA, serviço-escola de Psicologia da UFTM, pelo apoio na realização da pesquisa.

\section{CONFLTOS DE INTERESSES}

Não há conflitos de interesses.

\section{SOBRE AS AUTORAS}

Lara Pelliciari Veríssimo é psicóloga, bacharel em Psicologia pela Universidade Federal do Triângulo Mineiro (UFTM).

E-mail: lara.pelliciari@gmail.com

\section{(D) https://orcid.org/0000-0002-5668-817X}

Conceição Aparecida Serralha é Professora Associada do Programa de Pós-Graduação em Psicologia da Universidade Federal do Triângulo Mineiro (UFTM), com Mestrado e Doutorado em Psicologia Clínica pela Pontifícia Universidade Católica de São Paulo (PUC-SP) e pós-doutorado em Psicologia na Universidade Kennedy (UK) de Buenos Aires e em Filosofia da Psicanálise na Universidade Estadual de Campinas (UniCamp). Coordenadora do Laboratório de Estudos e Pesquisas em Psicanálise (LEPPse) da UFTM. 
E-mail: serralhac@hotmail.com

https://orcid.org/0000-0003-4916-7410 